\title{
Platelet Lysate as a Serum Substitute for 2D Static and 3D Perfusion Culture of Stromal Vascular Fraction Cells from Human Adipose Tissue
}

\author{
Andreas Marc Müller, M.D., ${ }^{1, *}$ Michael Davenport, B.Sc., ${ }^{1,}$ Sophie Verrier, Ph.D., ${ }^{2}$ Raoul Droeser, M.D., ${ }^{1}$ \\ Mauro Alini, Ph.D., ${ }^{2}$ Chiara Bocelli-Tyndall, Ph.D., ${ }^{1,3}$ Dirk J. Schaefer, M.D., ${ }^{4}$ \\ Ivan Martin, Ph.D., ${ }^{1}$ and Arnaud Scherberich, Ph.D. ${ }^{1}$
}

Fetal bovine serum (FBS) and fibroblast growth factor (FGF)-2 are key supplements for the culture of stromal vascular fraction (SVF) cells from adipose tissue, both for typical monolayer (2D) expansion and for streamlined generation of osteogenic-vasculogenic grafts in 3D perfusion culture. The present study investigates whether factors present in human platelet lysate (PL) could substitute for FBS and FGF-2 in 2D and 3D culture models of SVF cells from human lipoaspirates. SVF cells were grown in medium supplemented with $10 \%$ FBS + FGF-2 or with 5\% PL. In 2D cultures, PL initially supported SVF cell proliferation, but resulted in growth arrest shortly after the first passage. Freshly isolated SVF cells cultured with both media under perfusion for 5 days within 3D ceramic scaffolds induced bone formation after subcutaneous implantation in nude mice. However, blood vessels of donor origin were generated only using FBS + FGF-2-cultured cells. This was unexpected, because the proportion of $\mathrm{CD}^{+} 4^{+} / \mathrm{CD} 31^{+}$endothelial lineage cells was significantly higher with PL than that of FBS + FGF-2 (33\% vs. $3 \%$, respectively). These results support the use of PL as a substitute of FBS + FGF-2 for short-term culture of human SVF cells, and indicate that more specific serum-free formulations are required to maintain a functionally vasculogenic fraction of SVF cells expanded under 3D perfusion.

\section{Introduction}

$\mathbf{H}$ UMAN STROMAL VASCULAR FRACTION (SVF) cells derived from adipose tissue constitute a promising source of adult progenitor cells for autologous cell transplantation and tissue engineering. These progenitor cells can be obtained in abundance through minimally invasive, low morbidityassociated harvest procedures, for example, lipoaspiration, can extensively proliferate in 2D cultures, and can differentiate into multiple cell types, not only of the mesenchymal lineage, ${ }^{1,2}$ but also toward neuronal cells, ${ }^{3}$ cardiomyocytes, ${ }^{4}$ or hepatocytes. ${ }^{5}$ Recently, we have also demonstrated that mesenchymal and endothelial progenitors from human adipose tissue can be cocultured within 3D porous scaffolds under perfusion flow, resulting in osteogenic and vasculogenic properties after ectopic implantation in nude mice. ${ }^{6}$

Culture of SVF cells, both in 2D and 3D systems, typically involves the use of media containing fetal bovine serum (FBS), often further supplemented with fibroblast growth factor (FGF)-2, ${ }^{2,6}$ which was shown to be crucial to maintain their proliferative and differentiation potential. ${ }^{7,8}$ FBS is a typical component of standard culture media because it is a source of proteins promoting cell adhesion and of various growth factors stimulating cell proliferation. However, its use in the engineering of clinically compliant grafts raises concerns. As internalization of xenogenic FBS components in human mesenchymal progenitor cells may occur during the culture period, ${ }^{9}$ the transplantation of cells cultured with FBS into immunocompetent organisms opens the risk of immune reactions ranging from chronic rejection of transplanted cells to acute anaphylactic, life threatening immune responses. ${ }^{10,11}$ Additionally, the use of FBS bears the risk of transmitting prions as well as other known and unknown pathogens. To overcome the risk of infection and immune-related diseases, there have been attempts to replace FBS by autologous serum, for example, for the culture of mesenchymal stromal cells

\footnotetext{
${ }^{1}$ Tissue Engineering Group, Laboratory 405, Department of Biomedicine, Institute for Surgical Research and Hospital Management, University Hospital Basel, Basel, Switzerland.

${ }^{2}$ Biomaterials \& Tissue Engineering, AO Research Institute, Davos, Switzerland.

${ }^{3}$ University Department of Rheumatology, Felix Platter Spital, Basel, Switzerland.

${ }^{4}$ Clinic of Plastic, Reconstructive and Aesthetic Surgery, Department of Surgery, University Hospital Basel, Basel, Switzerland.

*These authors contributed equally to this work.
} 
(MSC) derived from bone marrow. Substantial expansion in autologous serum was reported, particularly in the first passages, ${ }^{12,13}$ but not to the extent required to obtain clinically relevant cell numbers. Recently, platelet lysate (PL) has been proposed as a potent substitute to FBS. Lysis of platelets releases granules containing various growth factors such as TGF- $\beta$, PDGF, IGF-1, EGF, and VEGF, as well as adhesive proteins involved in hemostasis (fibronectin and fibrinogen). PL is generally prepared from human blood according to standardized clinical-grade procedures and is subjected to careful and documented screening for most major infectious pathogens such as HIV, cytomegalovirus, or hepatitis B and C virus. It can thus be considered as a safe and clinically compliant alternative to bovine serum. Previous studies have demonstrated successful use of PL for the expansion of MSC from bone marrow ${ }^{14-16}$ or umbilical cord blood, ${ }^{17}$ as well as for the expansion of endothelial cells. ${ }^{18}$ Moreover, MSC expanded in the presence of PL were not tumorigenic when assessed in nude mice. ${ }^{16}$

In the present study, we investigated whether FBS and FGF-2 could be replaced by PL for typical expansion of SVF cells in monolayer on tissue culture plastic, and for 3D culture within porous scaffolds under perfusion flow. Characterization included assessment of cell growth and phenotype of the 2D expanded population, as well as in vivo tests of the osteogenic and vasculogenic capacity of the $3 \mathrm{D}$ grafts generated in the perfusion bioreactor system.

\section{Materials and Methods}

\section{Preparation of $P L$}

PL was obtained from seven different aphaeresis samples, each lot coming from a single donor, collected at the Blood Transfusion Center (Basel, Switzerland) according to Swiss legislation. The bags were obtained $4-5$ days after collection. Only samples containing at least $1 \times 10^{9}$ platelets $/ \mathrm{mL}$ were selected. PL samples were frozen overnight at $-80^{\circ} \mathrm{C}$ and then thawed to allow the release of the growth factors from the platelets. The platelet bodies were eliminated by centrifugation at $900 \mathrm{~g}$, the supernatant constituting the PL. To avoid gel formation by the PL, $2 \mathrm{IU} / \mathrm{mL}$ heparin (Roche, Basel, Switzerland) was added to the PL medium. Growth factor concentration was measured in four of the seven PL used in this study with commercially available enzyme-linked immunoabsorbent assay (ELISA) for PDGF and bFGF (antibody \#DHB00D and \#HSFB75, respectively, both from R\&D Systems, Abingdon, United Kingdom) and for TGF- $\beta 1$ (antibody \#559119 from Becton Dickinson, Allschwil, Switzerland) following the procedure recommended by the manufacturer.

\section{Cell isolation}

Subcutaneous adipose tissue in the form of lipoaspirates was obtained from thigh and/or abdominal adipose tissue of 16 healthy donors (all females, $47 \pm 23$ years old, body mass index $22.2 \pm 2.7 \mathrm{~kg} / \mathrm{m}^{2}$ ) during routine dermolipectomy, after approval by the internal ethics commission and with informed consent from the patients. The tissue was digested in a final concentration of $0.075 \%$ collagenase type $2(312 \mathrm{U} / \mathrm{mg}$; Worthington, Lakewood, NJ) for $45 \mathrm{~min}$ at $37^{\circ} \mathrm{C}$ on an orbital shaker. The suspension was thereafter centrifuged at $300 \mathrm{~g}$ for $10 \mathrm{~min}$; the resulting pellet (i.e., the SVF) was washed once with PBS, resuspended in $\alpha$-modified Eagle's medium $(\alpha-$ MEM) (Gibco Invitrogen, Basel, Switzerland), and finally filtered through a $100-\mu \mathrm{m}$ strainer (BD Falcon, Allschwill, Switzerland).

\section{Monolayer cell culture}

After isolation from the tissue of origin, nucleated SVF cells were seeded onto Petri dishes at a density of $2.7 \times 10^{3}$ cells $/ \mathrm{cm}^{2}$, in $\alpha$-MEM supplemented either with $10 \%$ FBS and $5 \mathrm{ng} / \mathrm{mL}$ FGF-2 (FBS + FGF-2), or with 5\% PL. In some experiments, PL was also supplemented at the concentration of $10 \%$. Cells were cultured for the indicated period of time in a humidified incubator at $37^{\circ} \mathrm{C}$ and $5 \% \mathrm{CO}_{2}$. The first expansion of SVF cells on tissue culture plastic was defined as $\mathrm{p} 0$. The first passage ( 1 1) was defined as the expansion phase right after the first replating. The number of clonogenic cells, generally referred to as colony-forming units-fibroblast, was determined by plating $5 \times 10^{2}$ SVF cells in medium containing FBS + FGF-2 in 10-cm-diameter Petri dishes, followed by counting the colonies visibly stained by crystal violet after 2 weeks. The proliferation rate was determined by counting the number of cells at the first plating (p0) and at the end of each subsequent passage (p1, p2, and p3), using a Neubauer chamber. The average number of cell doublings per day was defined as the total number of doublings during the culture period, calculated as the logarithm in base 2 of the ratio between the final and initial cell numbers, divided by the number of days in culture. The initial number of cells competent for adhesion and subsequent proliferation was assumed to correspond to the number of clonogenic cells, determined for each primary culture in parallel assays as described above.

\section{Cell culture under perfusion}

A perfusion bioreactor system was used for cell seeding and subsequent culture of freshly isolated cells from adipose tissue in 3D scaffolds, mostly as described previously. ${ }^{6,19,20}$ About $3 \times 10^{6}$ SVF cells were perfused for 5 days through 8-mm-diameter, 4-mm-thick Engipore ${ }^{\circledR}$ disks of porous hydroxyapatite ceramic (Fin-Ceramica, Faenza, Italy; average porosity of $83 \pm 3 \%$ ) in medium containing either $10 \%$ FBS and $5 \mathrm{ng} / \mathrm{mL}$ FGF-2 (FBS + FGF-2), or $5 \%$ PL. The flow rate of the perfusion through the disk was set at $3 \mathrm{~mL} / \mathrm{min}$.

\section{Construct implantation and in vivo bone formation assessment}

Constructs from independent experiments, after the 3D perfusion culture, were implanted ectopically in recipient nude mice (CD-1 nu/nu, 1 month old; Charles River Laboratories, Sulzfeld, Germany) in accordance with institutional guidelines. Eight weeks after implantation, mice were sacrificed, and the constructs were harvested and fixed overnight in $4 \%$ formalin, decalcified for $3 \mathrm{~h}$ with Osteodec (Bio-Optica, Milano, Italy) under agitation at $37^{\circ} \mathrm{C}$, paraffin embedded, and sectioned (7- $\mu$ m-thick sections) at different levels. Sections were then stained by hematoxylin-eosin and observed microscopically.

\section{Immunostaining of human blood vessels}

Tissue vascularization by endothelial cells of human origin was determined by immunohistochemical staining with 
a biotin-conjugated antibody recognizing the human isoform of CD34 (Chemicon, Hampshire, United Kingdom). After incubation with $\mathrm{ABC}^{\circledR}$-alkaline phosphatase complex (Dako, Baar, Switzerland), specific staining was revealed using Fast red from Dako. Sections were counterstained with hematoxylin and mounted.

\section{Cytofluorimetric analysis}

Cell suspensions were incubated for $30 \mathrm{~min}$ at $4{ }^{\circ} \mathrm{C}$ with fluorochrome-conjugated antibodies against the indicated protein, or an isotype control. All the antibodies were from Becton Dickinson, Allschwil, Switzerland except for CD105, which was from Serotec, Düsseldorf, Germany. Cells were washed and resuspended in PBS, and analyzed with a FACSCalibur flow cytometer.

\section{In vitro osteogenic differentiation}

SVF cells at $\mathrm{p} 1$ were cultured with osteoinductive medium for 3 weeks, with medium changes twice a week. Osteogenic medium consisted of $\alpha$-MEM supplemented with $10 \%$ FBS, $100 \mathrm{nM}$ dexamethasone, $10 \mathrm{mM}[\beta]$-glycerophosphate, and $0.05 \mathrm{mM}$ ascorbic acid-2-phosphate. The cells cultured in $\alpha$ MEM with FBS + FGF-2 served as controls. Cell layers were washed twice with PBS, fixed for $10 \mathrm{~min}$ with $4 \%$ formalin, and stained with $2 \%$ alizarin red $S$.

\section{Results}

\section{D monolayer cultures}

Concentrations of FGF-2, TGF- $\beta 1$, and PDGF-AB were measured in four of the PL used in this study and averaged, respectively, $0.11 \pm 0.05,56.1 \pm 26.6$, and $18.3 \pm 2.1 \mathrm{ng} / \mathrm{mL}$. After the first passage in monolayers, corresponding to about 4-5 doublings, SVF cells cultured with FBS + FGF-2 exhibited a typical fibroblastic morphology, whereas cells cultured with PL showed a more elongated, heterogeneous population of cells, with formation of circular structures (Fig. 1A). Proliferation of SVF cells was derived during the first expansion (p0) and at the first three passages. SVF cells cultured with FBS + FGF-2 had an initial doubling rate of $1.0 \pm 0.2$ doublings/day, as compared to $0.7 \pm 0.2$ for PL. The proliferation rate of cells cultured with PL dramatically decreased to $0.14 \pm 0.15$ doublings/day after the first re-plating (p1) and further reduced to $0.07 \pm 0.05$ at $\mathrm{p} 2$, and no proliferation was observed at p3 (Fig. 1B, closed squares). At the corresponding passages, SVF cells cultured with FBS+FGF-2 proliferated steadily, with average proliferation rates of around 0.5

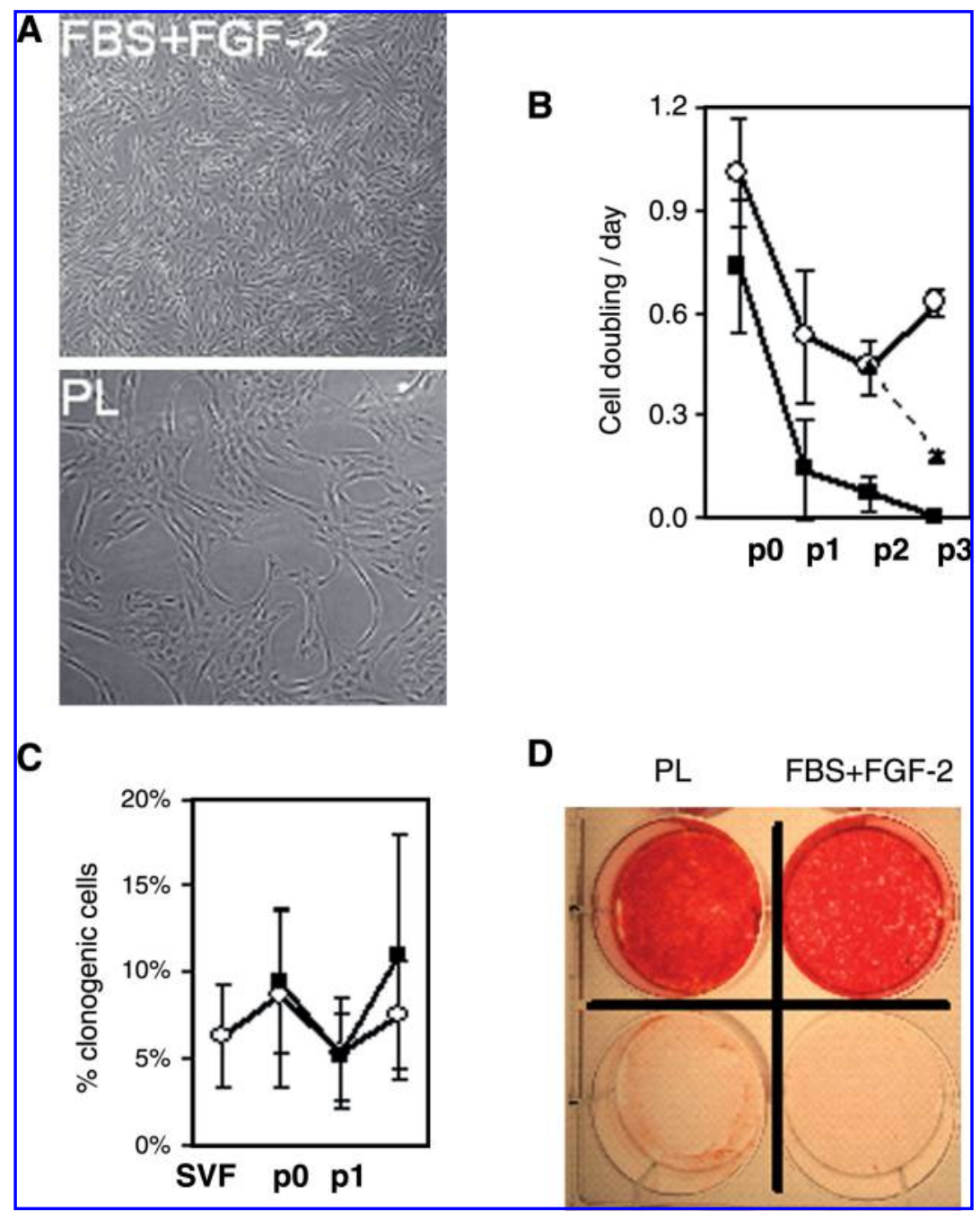

FIG. 1. Comparison between SVF cells expanded in an FBS-containing medium supplemented with FGF-2 (FBS +

FGF-2) and a serum-free medium supplemented only with PL. (A) Microscopic picture showing the morphology of SVF cells cultured on tissue culture plastic, at p1. (B) Proliferation rate of SVF cells on tissue culture plastic at different passages (from p0 to p3, as indicated), expressed as number of cell doubling per day. Open circles, FBS + FGF-2; closed squares, PL; closed triangles, SVF cells initially expanded with FBS +FGF-2 until the end of p1 and thereafter switched to PL. (C) Colonyforming efficiency of SVF cells at different passages (from freshly isolated SVF cells to p2). Results are expressed as percentage of colony-forming cells. Open circles, FBS + FGF-2; closed squares, PL. (D) In vitro osteoblastic differentiation of SVF cells at the end of p2. SVF cells cultured with either FBS + FGF-2 or PL on plastic until p1 were further cultured for 3 weeks and stained with alizarin red. Top row: FBScontaining medium supplemented with osteogenic supplements (dexamethasone, ascorbate, and $\beta$-glycerophosphate). Bottom row: FBS-containing medium only. Color images available online at www.liebertonline.com/ten. 
doubling/day (Fig. 1B, open circles). When SVF cells expanded with FBS + FGF-2 until p2 were switched to serumfree medium containing PL only, the cell expansion rate dropped immediately to a total arrest after 1-2 passages (Fig. $1 \mathrm{~B}$, closed triangles). Neither addition of $5 \mathrm{ng} / \mathrm{mL} \mathrm{FGF-2} \mathrm{to} 5 \%$ PL nor increase of the PL concentration to $10 \%$ was able to prevent the growth arrest of SVF cells at p2.

At each passage, the clonogenic potential of SVF cells was determined by colony formation assays. Freshly isolated SVF cells exhibited a $6 \pm 3 \%$ colony-forming cell frequency, which remained mostly constant in the range of $5-10 \%$ in the cultures until p2, with no significant differences between PL and FBS + FGF-2 (Fig. 1C). The clonogenic frequency remained similar also if SVF cells were expanded with PL further supplemented with $5 \mathrm{ng} / \mathrm{mL}$ FGF-2 $(9 \pm 3 \%, n=3$ independent donors). At different passages, the differentiation potential of expanded SVF cells was evaluated by in vitro mineralization assay. After exposure to osteogenic supplements, SVF cells expanded until p2 using PL or FBS + FGF-2 deposited extensive mineralized matrix, as assessed by alizarin red staining (Fig. 1D).

At different passages in 2D cultures, the phenotype of SVF cells was investigated by flow cytometry (Fig. 2). The markers expressed by freshly isolated SVF cells were mostly in accordance with our previous data. ${ }^{6}$ In cells expanded with FBS + FGF-2, a typical enrichment in mesenchymal lineage cells, characterized by expression of CD90 and CD105, was already observed at $\mathrm{p} 0$. The mesenchymal cell population represented approximately $100 \%$ of the cells at p1 and p2. In cells cultured with PL, despite enrichment in stromal cells, an important fraction of cells of the endothelial lineage $\left(33 \pm 26 \%\right.$ of $\mathrm{CD} 34^{+} / \mathrm{CD} 31^{+}$cells) remained present until the end of $\mathrm{p} 0$, and was gradually lost after p1. Double la- beling for CD31 and CD34 indicated that at each passage in FBS + FGF-2 medium all cells positive for CD34 were negative for CD31, whereas in PL medium the cells positive for CD34 were also all positive for CD31 (data not shown). A population of cells positive for CD31 and the chemokine receptor CXCR4 was present at p1 and p2, but only with PL. This population was of the mesenchymal lineage, as assessed by positivity for CD90 (data not shown).

\section{D Perfusion cultures}

We next investigated the bone and blood vessel formation capacity of SVF cells expanded for 5 days within porous ceramic scaffolds in a 3D perfusion system, bypassing the typical 2D expansion phase. Cells were cultured either with FBS + FGF-2 or with PL only, and the resulting constructs were assessed using an ectopic in vivo bone and blood vessel formation model. ${ }^{6}$ After 8 weeks of implantation, sparse bone tissue was formed in both experimental conditions (Fig. 3A-D). No bone formation was observed when cell-free scaffolds were implanted in the same ectopic model. ${ }^{6}$ In three independent experiments performed using SVF cells from three different donors, cells cultured with FBS + FGF-2 also produced blood vessels, as documented by immunostaining for human CD34. In particular, we observed a mix of unstained blood vessels of mouse (recipient) origin and positively stained blood vessels of human (donor) origin (Fig. 3E), which were connected to the vasculature of the host, as indicated by the presence of erythrocytes in their lumen. Unexpectedly, SVF cells grown under perfusion for 5 days with PL failed to generate human blood vessels in vivo, and only mouse-derived blood vessels were visible (Fig. 3F).
FIG. 2. Cytofluorimetric analysis of SVF cells and of SVF cells grown on tissue culture plastic with the indicated medium, at different passages from $\mathrm{p} 0$ to $\mathrm{p} 2$. Results are expressed as percentage of cells positive for the indicated markers.

\begin{tabular}{|c|c|c|c|c|c|}
\hline & & SVF & po & FBS $+F G F-2$ & PL \\
\hline \multicolumn{2}{|c|}{ CD14 } & $23 \pm 8 \%(n=6)$ & CD14 & $2 \pm 2 \%(n=8)$ & $3 \pm 5 \%(\mathrm{r}=7)$ \\
\hline \multicolumn{2}{|c|}{ CD45 } & $41 \pm 21 \%(n=6)$ & CD45 & $1 \pm 1 \%(n=9)$ & $1 \pm 1 \%(\mathrm{r}=9)$ \\
\hline \multicolumn{2}{|c|}{ CD34 } & $42 \pm 23 \%(n=6)$ & CD34 & $20 \pm 26 \%(n=9)$ & $33 \pm 26 \%(n=8)$ \\
\hline \multicolumn{2}{|c|}{ CD31 } & $31 \pm 19 \%(n=6)$ & CD31 & $3 \pm 5 \%(n=9)$ & $33 \pm 26 \%(n=8)$ \\
\hline \multicolumn{2}{|c|}{ CD90 } & $38 \pm 18 \%(n=6)$ & CD90 & $89 \pm 12 \%(n=8)$ & $69 \pm 24 \%(n=8)$ \\
\hline \multicolumn{2}{|c|}{ CD146 } & $12 \pm 6 \%(n=4)$ & CD146 & $42 \pm 20 \%(n=4)$ & $12 \pm 9 \%(n=3)$ \\
\hline \multicolumn{2}{|c|}{ CXCR4 } & $8 \pm 5 \%(n=3)$ & CXCR4 & $0 \%(n=3)$ & $4 \pm 6 \%(n=3)$ \\
\hline \multicolumn{2}{|c|}{ CD105 } & $16 \pm 12 \%(n=5)$ & CD105 & $85 \pm 21 \%(n=3)$ & $65 \pm 35 \%(n=3)$ \\
\hline$p 1$ & FBS+FGF-2 & PL & p2 & FBS+FGF-2 & PL \\
\hline $\mathrm{CD} 14$ & $0 \pm 1 \%(n=4)$ & $1 \pm 1 \%(n=4)$ & & & \\
\hline CD45 & $0 \%(n=4)$ & $5 \pm 12 \%(n=4)$ & CD45 & $0 \%(n=2)$ & $4 \pm 6 \%(n=2)$ \\
\hline CD34 & $6 \pm 10 \%(n=4)$ & $2 \pm 2 \%(n=4)$ & CD34 & $3 \pm 6 \%(r=3)$ & $11 \pm 10 \%(n=3)$ \\
\hline CD31 & $2 \pm 4 \%(n=4)$ & $8 \pm 13 \%(n=4)$ & CD31 & $0 \%(n=3)$ & $21 \pm 3 \%(n=3)$ \\
\hline CD90 & $96 \pm 2 \%(\mathrm{r}=4)$ & $91 \pm 6 \%(n=4)$ & CD90 & $97 \pm 3 \%(n=3)$ & $83 \pm 8 \%(n=2)$ \\
\hline CD146 & $16 \pm 10 \%(\mathrm{r}=4)$ & $6 \pm 4 \%(n=3)$ & CD146 & $0 \%(n=2)$ & $3 \pm 5 \%(n=3)$ \\
\hline CXCR4 & $0 \%(n=3)$ & $14 \pm 29 \%(n=3)$ & CXCR4 & $0 \%(n=3)$ & $14 \pm 5 \%(n=2)$ \\
\hline CD105 & $92 \pm 5 \%(\mathrm{r}=3)$ & $61 \pm 11 \%(n=3)$ & CD10s & $76 \pm 14 \%(n=2)$ & $73 \pm 10 \%(n=2)$ \\
\hline
\end{tabular}




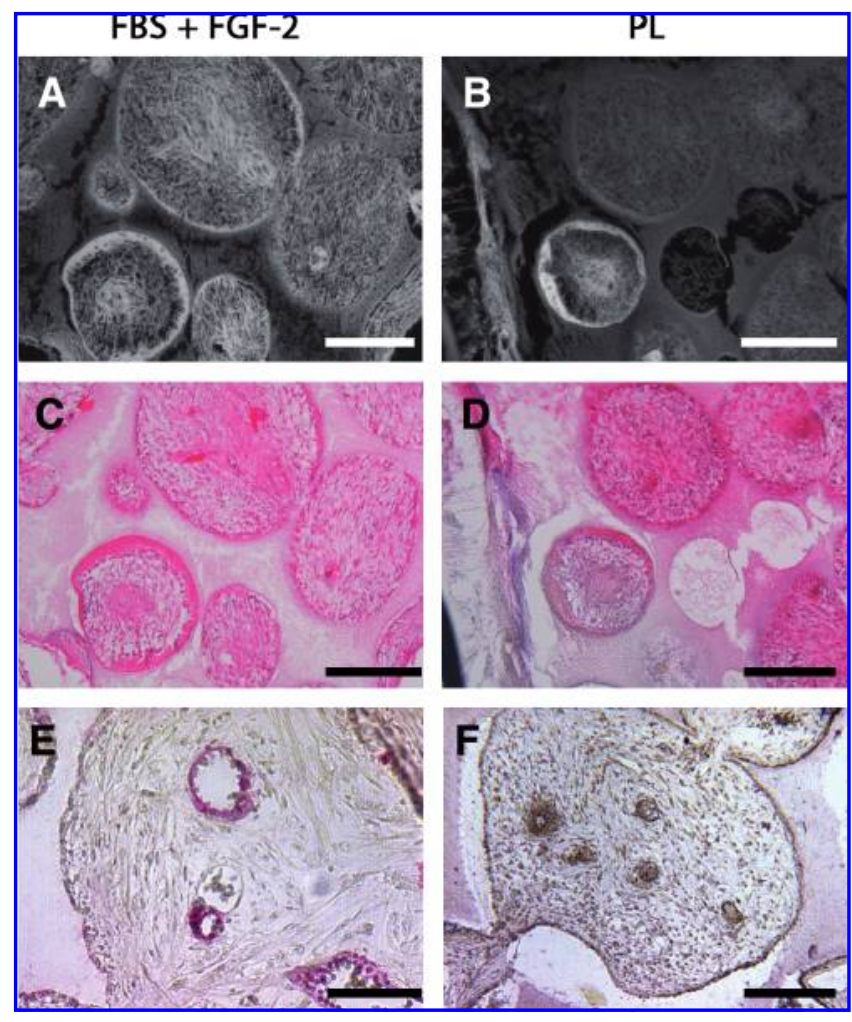

FIG. 3. Histology of SVF cell-hydroxyapatite constructs after 8 weeks of ectopic in vivo implantation in nude mouse. (A-D) Bars $200 \mu \mathrm{m}$. Fluorescence pictures (top row) and hematoxylin-eosin staining (bottom row). (E, F) Bars $100 \mu \mathrm{m}$. Immunohistochemical staining for human CD34. Color images available online at www.liebertonline.com/ten.

\section{Discussion}

The present study provides a proof-of-principle on the efficacy of PL to substitute for FBS + FGF-2 in the culture of human SVF cells in different systems. However, our findings also highlight potential limits for the use of PL, related to (i) a reduced extent of cell expansion in $2 \mathrm{D}$ cultures and (ii) the lack of a cell fraction with in vivo vasculogenic capacity in 3D perfusion cultures.

In 2D cultures on plastic, PL supported growth of SVF cells at least until the first passage. Interestingly, the proliferation of SVF cells cultured in the presence of PL for more than one passage restarted when switching them to a medium supplemented with FBS + FGF-2, as demonstrated by the transfer into the clonogenicity assay cultures. This capacity to further grow even under stringent low-density conditions indicates the preservation of some features of progenitor cells, and reassures the use of PL as a serum substitute, in case only a limited extent of SVF cells is required. However, the expansion of SVF cells over several passages was not feasible, and PL induced almost a growth arrest shortly after the first passage. This result is in apparent conflict with another report by Mirabet et al. indicating that adipose-derived cells can be expanded with PL $^{21}$ over many passages. However, several points make difficult the comparison of that study with ours, including the different procedure for preparation of PL (respectively using submersion into liquid nitrogen vs. the use of a $-70^{\circ} \mathrm{C}$ freezer) and the different density of platelets before lysis (respectively $4 \times 10^{9}$ platelets/mL vs. $1-2 \times 10^{9}$ ). Moreover, Mirabet et al. assessed the proliferation of SVF cells in PL-supplemented medium only after a first culture phase in the presence of FBS, whereas we started the serum-free expansion immediately after cell isolation, to avoid any possible contamination from FBS in view of a potential clinical approach. Concentrations of PDGF-AB and TGF- $\beta 1$ in the PL used in the present study were measured and were similar to those described in other studies ${ }^{22,23}$ using PL able to support in vitro expansion of bone marrow-derived stromal cells. It is thus unlikely that the growth arrest observed here could be due to improper preparation or storage of PL.

There are promising alternatives to the use of PL for the serum-free expansion of SVF cells. Kocaoemer et al. ${ }^{24}$ used thrombin-activated platelet-rich plasma (tPRP) instead of PL, based on the assumption that a more physiological activation of platelets by thrombin should result in a more efficient cocktail of growth factors, and managed to establish longterm cultures of SVF cells using a serum-free medium supplemented with $\mathrm{tPRP}$. The performance of pooled human AB serum was also tested in the same study, and the results were similar to tPRP or FCS, in accordance with another report showing that low doses of human serum $(0.5 \%)$ can support expansion of SVF cells similarly to $10 \% \mathrm{FBS}^{25}$ Nevertheless, supplementations with PL, tPRP, or human serum in previous studies were always evaluated in vitro only and could not fully and reliably document the in vivo performance of the cells expanded with these different FCS substitutes. Future studies should aim at investigating the potential of human serum or tPRP in an in vivo setup like in the present study.

In addition to several other growth factors, such as PDGFAB, PDGF-BB, IGF- 1 , TGF- $\beta 1$, EGF, and VEGF, PL contains a typical concentration of $0.1 \mathrm{ng} / \mathrm{mL}$ of FGF-2, ${ }^{2,16}$ corresponding to a final concentration in the test culture medium of approximately $5 \mathrm{pg} / \mathrm{mL}$. We found a similar concentration of FGF-2 in our preparations of PL. Because this concentration is about 1000 -fold lower than that of the FBS + FGF-2 experimental condition (i.e., $5 \mathrm{ng} / \mathrm{mL}$ ), we tested whether further supplementation of FGF-2 to PL could support SVF cell expansion to a larger extent. The lack of a measurable effect suggests that low levels of FGF-2 were likely not the factor responsible for growth arrest of SVF cells, and leaves open the possibility that in addition to known mitogenic factors, PL contains also growth inhibitory factors, contrasting the effect of FGF-2 on SVF cells.

SVF cells were initially highly heterogeneous in phenotype, including mesenchymal-, monocytic-, hemopoietic-, and endothelial-lineage populations. During 2D expansion in either FBS + FGF-2 or PL, the majority of the cells were of mesenchymal origin, which is consistent with previous reports, ${ }^{26,27}$ although PL supported the maintenance of a larger fraction of cells double positive for CD31 and CD34 than FBS + FGF-2. Interestingly, a population of cells positive for CXCR4 was maintained only in the presence of PL. Expression of CXCR4 was reported to be expressed by $\mathrm{CD} 34^{+} / \mathrm{CD} 31^{-}$cells, implicated in the formation of a vascular network during the development of human adipose tissue. ${ }^{28}$ However, expression of CXCR4 was here associated to mesenchymal cells $\left(\mathrm{CD} 90^{+}\right)$ and not to endothelial progenitors $\left(\mathrm{CD} 34^{+} / \mathrm{CD} 31^{-}\right)$, indicating a distinct phenotype and possibly function from that previously reported. 
SVF cells freshly isolated and cultured under perfusion within porous ceramic scaffolds for 5 days in medium supplemented with FBS + FGF-2 or PL were both osteogenic when subcutaneously implanted in nude mice. Although the reproducibility and uniformity of in vivo bone formation in this study were not extensively investigated, the results provide a proof-of-principle that PL can be used for the streamlined generation of osteogenic grafts within perfusion-based bioreactor systems. Using the same model, we also found that blood vessels of human origin were formed after culture with FBS + FGF-2, but not with PL. This result was rather unexpected because, after 2D expansion, PL maintained notably more endothelial progenitors $\left(\mathrm{CD} 31^{+} / \mathrm{CD} 34^{+}\right.$cells) than FBS $+\mathrm{FGF}-2(33 \%$ vs. $3 \%$, respectively). Assuming a correspondence of cell phenotypes in 2D and $3 \mathrm{D}$ cultures, one possible explanation could be related to the lack of CD34 ${ }^{+} / \mathrm{CD} 31^{-}$cells in the presence of PL. In fact, it was recently shown that $\mathrm{CD} 34^{+} / \mathrm{CD} 31^{-}$cells derived from adipose tissue express pericytic markers such as NG2 proteoglycan ${ }^{29}$ and could thus play a role in vascular stabilization by functional interaction with endothelial cells. Along this theory, it should be highlighted that another marker of perivascular cells, namely, $\mathrm{CD}_{146}{ }^{+}$, was more largely expressed in the presence of FBS + FGF- 2 than of PL ( $42 \%$ vs. $12 \%$ after the first passage). It is thus possible that $\mathrm{PL}$ is not efficient in maintaining pericytic cells resident in the SVF, and this would result in the lack of functionality of the endothelial lineage cells present in the graft. The consequence of lacking a functional vasculogenic cell fraction in the presence of PL is currently unclear for the performance of SVF-derived bone grafts. The issue should be investigated in models addressing the kinetics of blood vessel formation within grafts (i.e., skin-fold chamber model ${ }^{30}$ ), as well as using larger constructs, where rapid and efficient vascularization is crucial to reduce formation of a necrotic core. ${ }^{31}$

Despite the discussed limitations, PL appears to be a promising serum substitute for the short-term 2D expansion of SVF cells and for their culture in 3D perfusion systems. As concerning the potential amount of expanded cells available using PL for therapeutic purposes, it has to be considered that adipose biopsies of $200 \mathrm{~mL}$ to $1 \mathrm{~L}$ could be obtained from a donor for clinical application without significant related morbidity. Based on the present study, starting from as few as $100 \mathrm{~mL}$ of adipose tissue, an average of $20 \times 10^{6}$ SVF cells were isolated, which after 5 days of culture in PL-supplemented medium would potentially result in the generation of $2-4 \times 10^{7}$ expanded cells (i.e., $2-4 \times 10^{8}$ if $1 \mathrm{~L}$ was used). This would largely exceed the need of expanded cells for most of the clinical applications envisioned for adiposederived cells. These results support the establishment of a bone tissue engineering model based on minimally invasive harvesting adipose tissue, then extracting the SVF cells, and perfusing them in a bioreactor for 5 days in a serum-free medium supplemented with possibly autologous PL, to generate osteogenic grafts for bone replacement. The system would require only animal-free medium supplements, and the elimination of the $2 \mathrm{D}$ expansion phase would represent a step forward to the development of streamlined, automated, and possibly more cost-effective manufacturing processes.

\section{Acknowledgments}

We are grateful to Dr. Iradj Farhadi for providing us adipose tissue samples. We thank also the Blutspendezentrum
SRK Beider Basel (Basel, Switzerland) for the supply of erythrocyte concentrates and Roberta Martinetti (FinCeramica Faenza S.p.a, Italy) for the generous supply of Engipore scaffolds. We acknowledge the European Union for financial support (European project STEPS, FP6, contract number NMP3-CT-2005-500465; http://www.stepsproject .com).

\section{Disclosure Statement}

No competing financial interests exist.

\section{References}

1. Gronthos, S., Franklin, D.M., Leddy, H.A., Robey, P.G., Storms, R.W., and Gimble, J.M. Surface protein characterization of human adipose tissue-derived stromal cells. J Cell Physiol 189, 54, 2001.

2. Zuk, P.A., Zhu, M., Ashjian, P., de Ugarte, D.A., Huang, J.I., Mizuno, H., Alfonso, Z.C., Fraser, J.K., Benhaim, P., and Hedrick, M.H. Human adipose tissue is a source of multipotent stem cells. Mol Biol Cell 13, 4279, 2002.

3. Safford, K.M., Hicok, K.C., Safford, S.D., Halvorsen, Y.D., Wilkison, W.O., Gimble, J.M., and Rice, H.E. Neurogenic differentiation of murine and human adipose-derived stromal cells. Biochem Biophys Res Commun 294, 371, 2002.

4. Planat-Benard, V., Menard, C., Andre, M., Puceat, M., Perez, A., Garcia-Verdugo, J.M., Penicaud, L., and Casteilla, L. Spontaneous cardiomyocyte differentiation from adipose tissue stroma cells. Circ Res 94, 223, 2004.

5. Seo, M.J., Suh, S.Y., Bae, Y.C., and Jung, J.S. Differentiation of human adipose stromal cells into hepatic lineage in vitro and in vivo. Biochem Biophys Res Commun 328, 258, 2005.

6. Scherberich, A., Galli, R., Jaquiery, C., Farhadi, J., and Martin, I. Three-dimensional perfusion culture of human adipose tissue-derived endothelial and osteoblastic progenitors generates osteogenic constructs with intrinsic vascularization capacity. Stem Cells 25, 1823, 2007.

7. Quarto, N., and Longaker, M.T. FGF-2 inhibits osteogenesis in mouse adipose tissue-derived stromal cells and sustains their proliferative and osteogenic potential state. Tissue Eng 12, 1405, 2006.

8. Zaragosi, L.E., Ailhaud, G., and Dani, C. Autocrine fibroblast growth factor 2 signaling is critical for self-renewal of human multipotent adipose-derived stem cells. Stem Cells 24, 2412, 2006.

9. Gregory, C.A., Reyes, E., Whitney, M.J., and Spees, J.L. Enhanced engraftment of mesenchymal stem cells in a cutaneous wound model by culture in allogenic species-specific serum and administration in fibrin constructs. Stem Cells 24, 2232, 2006.

10. Selvaggi, T.A., Walker, R.E., and Fleisher, T.A. Development of antibodies to fetal calf serum with arthus-like reactions in human immunodeficiency virus-infected patients given syngeneic lymphocyte infusions. Blood 89, 776, 1997.

11. Sotiropoulou, P.A., Perez, S.A., Gritzapis, A.D., Baxevanis, C.N., and Papamichail, M. Interactions between human mesenchymal stem cells and natural killer cells. Stem Cells 24, 74, 2006.

12. Mizuno, N., Shiba, H., Ozeki, Y., Mouri, Y., Niitani, M., Inui, T., Hayashi, H., Suzuki, K., Tanaka, S., Kawaguchi, H., and Kurihara, H. Human autologous serum obtained using a completely closed bag system as a substitute for foetal calf serum in human mesenchymal stem cell cultures. Cell Biol Int 30, 521, 2006. 
13. Stute, N., Holtz, K., Bubenheim, M., Lange, C., Blake, F., and Zander, A.R. Autologous serum for isolation and expansion of human mesenchymal stem cells for clinical use. Exp Hematol 32, 1212, 2004.

14. Bernardo, M.E., Avanzini, M.A., Perotti, C., Cometa, A.M., Moretta, A., Lenta, E., Del, F.C., Novara, F., de, S.A., Amendola, G., Zuffardi, O., Maccario, R., and Locatelli, F. Optimization of in vitro expansion of human multipotent mesenchymal stromal cells for cell-therapy approaches: further insights in the search for a fetal calf serum substitute. J Cell Physiol 211, 121, 2007.

15. Lange, C., Cakiroglu, F., Spiess, A.N., Cappallo-Obermann, H., Dierlamm, J., and Zander, A.R. Accelerated and safe expansion of human mesenchymal stromal cells in animal serum-free medium for transplantation and regenerative medicine. J Cell Physiol 213, 18, 2007.

16. Schallmoser, K., Bartmann, C., Rohde, E., Reinisch, A., Kashofer, K., Stadelmeyer, E., Drexler, C., Lanzer, G., Linkesch, W., and Strunk, D. Human platelet lysate can replace fetal bovine serum for clinical-scale expansion of functional mesenchymal stromal cells. Transfusion 47, 1436, 2007.

17. Reinisch, A., Bartmann, C., Rohde, E., Schallmoser, K., BjelicRadisic, V., Lanzer, G., Linkesch, W., and Strunk, D. Humanized system to propagate cord blood-derived multipotent mesenchymal stromal cells for clinical application. Regen Med 2, 371, 2007.

18. Miyazono, K., Okabe, T., Ishibashi, S., Urabe, A., and Takaku, F. A platelet factor stimulating the proliferation of vascular endothelial cells. Partial purification and characterization. Exp Cell Res 159, 487, 1985.

19. Braccini, A., Wendt, D., Jaquiery, C., Jakob, M., Heberer, M., Kenins, L., Wodnar-Filipowicz, A., Quarto, R., and Martin, I. Three-dimensional perfusion culture of human bone marrow cells and generation of osteoinductive grafts. Stem Cells 23, 1066, 2005.

20. Wendt, D., Marsano, A., Jakob, M., Heberer, M., and Martin, I. Oscillating perfusion of cell suspensions through threedimensional scaffolds enhances cell seeding efficiency and uniformity. Biotechnol Bioeng 84, 205, 2003.

21. Mirabet, V., Solves, P., Minana, M.D., Encabo, A., CarbonellUberos, F., Blanquer, A., and Roig, R. Human platelet lysate enhances the proliferative activity of cultured human fibroblast-like cells from different tissues. Cell Tissue Bank 9, 1, 2008.

22. Doucet, C., Ernou, I., Zhang, Y., Llense, J.R., Begot, L., Holy, $X$. and Lataillade, J.J. Platelet lysates promote mesenchymal stem cell expansion: a safety substitute for animal serum in cell-based therapy applications. J Cell Physiol 205, 228, 2005.

23. El-Sharkawy, H., Kantarci, A., Deady, J., Hasturk, H., Liu, H., Alshahat, M., and van Dyke, T.E. Platelet-rich plasma: growth factors and pro- and anti-inflammatory properties. J Periodontol 78, 661, 2007.

24. Kocaoemer, A., Kern, S., Kluter, H., and Bieback, K. Human $\mathrm{AB}$ serum and thrombin-activated platelet-rich plasma are suitable alternatives to fetal calf serum for the expansion of mesenchymal stem cells from adipose tissue. Stem Cells 25, 1270, 2007.

25. Parker, A.M., Shang, H., Khurgel, M., and Katz, A.J. Low serum and serum-free culture of multipotential human adipose stem cells. Cytotherapy 9, 637, 2007.

26. de Girolamo, L., Sartori, M.F., Albisetti, W., and Brini, A.T. Osteogenic differentiation of human adipose-derived stem cells: comparison of two different inductive media. J Tissue Eng Regen Med 1, 154, 2007.

27. Minana, M.D., Carbolell-Uberos, F., Mirabet, V., Marin, S., and Encabo, A. IFATS Series: identification of hemangioblasts in the adult human adipose tissue. Stem Cells 26, 2696, 2008.

28. Sengenes, C., Miranville, A., Maumus, M., de, B.S., Busse, R., and Bouloumie, A. Chemotaxis and differentiation of human adipose tissue $\mathrm{CD} 34+/ \mathrm{CD} 31$-progenitor cells: role of stromal derived factor-1 released by adipose tissue capillary endothelial cells. Stem Cells 25, 2269, 2007.

29. Traktuev, D.O., Merfeld-Clauss, S., Li, J., Kolonin, M., Arap, W., Pasqualini, R., Johnstone, B.H., and March, K.L. A population of multipotent CD34-positive adipose stromal cells share pericyte and mesenchymal surface markers, reside in a periendothelial location, and stabilize endothelial networks. Circ Res 102, 77, 2008.

30. Rucker, M., Laschke, M.W., Junker, D., Carvalho, C., Schramm, A., Mulhaupt, R., Gellrich, N.C., and Menger, M.D. Angiogenic and inflammatory response to biodegradable scaffolds in dorsal skinfold chambers of mice. Biomaterials 27, 5027, 2006.

31. Scheufler, O., Schaefer, D.J., Jaquiery, C., Braccini, A., Wendt, D.J., Gasser, J.A., Galli, R., Pierer, G., Heberer, M., and Martin, I. Spatial and temporal patterns of bone formation in ectopically pre-fabricated, autologous cell-based engineered bone flaps in rabbits. J Cell Mol Med 12, 1238, 2008.

Address reprint requests to: Ivan Martin, Ph.D.

Tissue Engineering Group Laboratory 405

Department of Biomedicine

Institute for Surgical Research and Hospital Management University Hospital Basel Hebelstrasse 20

CH-4031 Basel Switzerland

E-mail: martini@uhbs.ch

Received: September 5, 2008

Accepted: December 17, 2008

Online Publication Date: January 30, 2009 
